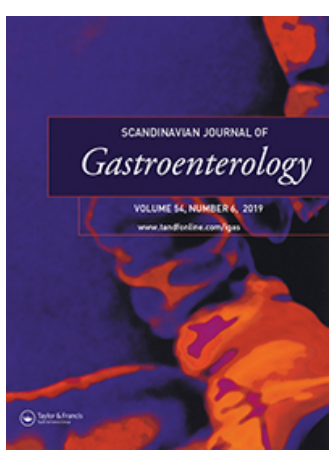

Scandinavian Journal of Gastroenterology

\title{
Optimizing the timing of colorectal surgery in patients with familial adenomatous polyposis in clinical practice
}

Hans F. A. Vasen, Zeinab Ghorbanoghli, Bastian de Ruijter, Ro-Anne Trinidad, Alexandra M. J. Langers, Koen C. M. J. Peeters, Bert A. Bonsing \& James C. H. Hardwick

To cite this article: Hans F. A. Vasen, Zeinab Ghorbanoghli, Bastian de Ruijter, Ro-Anne Trinidad, Alexandra M. J. Langers, Koen C. M. J. Peeters, Bert A. Bonsing \& James C. H. Hardwick (2019) Optimizing the timing of colorectal surgery in patients with familial adenomatous polyposis in clinical practice, Scandinavian Journal of Gastroenterology, 54:6, 733-739, DOI: 10.1080/00365521.2019.1621930

To link to this article: https://doi.org/10.1080/00365521.2019.1621930

曲 Published online: 11 Aug 2019.

Submit your article to this journal $₫$

Џ Article views: 32

Q View related articles $\widetilde{ }$

View Crossmark data $\nearrow$ 


\title{
Optimizing the timing of colorectal surgery in patients with familial adenomatous polyposis in clinical practice
}

\author{
Hans F. A. Vasen ${ }^{a, b}$, Zeinab Ghorbanoghlia, ${ }^{a}$, Bastian de Ruijter ${ }^{a}$, Ro-Anne Trinidad ${ }^{c}$, Alexandra M. J. Langers ${ }^{a}$, \\ Koen C. M. J. Peeters ${ }^{d}$, Bert A. Bonsing ${ }^{d}$ and James C. H. Hardwick ${ }^{a}$

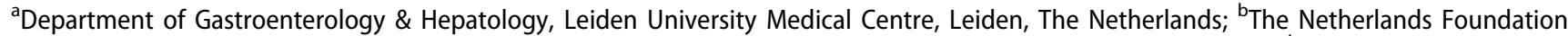
for the Detection of Hereditary Tumours, Leiden, The Netherlands; ${ }^{~ C J G ~ R i j n m o n d, ~ R o t t e r d a m, ~ T h e ~ N e t h e r l a n d s ; ~}{ }^{\mathrm{d} D e p a r t m e n t}$ of Surgery,
\end{abstract} \\ Leiden University Medical Centre, Leiden, The Netherlands
}

\begin{abstract}
Background: Familial adenomatous polyposis (FAP) is characterized by the development of hundreds of colorectal adenomas in the second decade of life, and prophylactic colectomy is usually performed around age of 20. A common question is the appropriate timing of surgery and which endoscopic findings indicate surgery.

Methods: All FAP patients known at Leiden University Medical Centre from 1985 onwards were included. The patients were then subdivided into those diagnosed before or after 2000. Patient information included age at diagnosis, colonic phenotype, age at surgery, pathological findings and the outcome of follow-up colonoscopies in whom surgery was postponed.

Results: The 72 FAP patients identified consisted of 33 patients diagnosed before (group A) and 39 after (group B) 2000. The median age at diagnosis for patients with classical FAP was 18 in groups A and B. All patients diagnosed before 2000 underwent colorectal surgery versus $68 \%$ of those diagnosed $>2000$. The median age at surgery for classical FAP patients was 19 and 24 years in groups A and $B$, respectively. In patients with intact colon, the number of adenomas gradually increased over many years. Although most adenomas remained $<5 \mathrm{~mm}$, the proportion of $5-15 \mathrm{~mm}$ adenomas slowly increased. Only one patient developed a high-grade adenoma. None of the patients developed CRC. Conclusions: Surgery today in FAP is performed less often and at a more advanced age. Our experience also suggests that surgery can be safely postponed in selected patients. The most important endoscopic indication for surgery is substantial number of large adenomas of $>5-10 \mathrm{~mm}$.
\end{abstract}

\section{ARTICLE HISTORY}

Received 30 December 2018

Revised 11 April 2019

Accepted 12 May 2019

\section{KEYWORDS}

Familial adenomatous polyposis (FAP); attenuated familial adenomatous polyposis (AFAP); surgical treatment; colectomy; sulindac

\section{Introduction}

Familial adenomatous polyposis (FAP) is a dominantly inherited syndrome caused by a mutation in the APC gene and characterized by the development of hundreds of adenomas in the colon and certain extracolonic features [1]. Colorectal adenomas usually develop in the second decade of life and if patients are left untreated, nearly all will develop cancer between the ages of 30 and 40 years [2]. However, about $10-20 \%$ of cases show a mild polyposis phenotype, which is referred to as 'attenuated familial adenomatous polyposis' (AFAP) [3]. This subtype of FAP is associated with specific mutations located at the extreme ends of the APC gene and in exon 9 [4].

Since the establishment of polyposis registries worldwide, the identification of families and the subsequent implementation of screening programs have substantially reduced CRC incidence and CRC-associated mortality [5,6]. Prophylactic (procto- or subtotal) colectomy is the mainstay of treatment for patients with polyposis [7]. However, there is currently no agreement on the timing of colorectal surgery.

Formerly, the presence of multiple colorectal adenomas independent of the number - together with the identification of an underlying APC gene mutation was an indication for surgical resection of the colon, in most centres usually carried out in the late teens. For example, at the polyposis registry of St Marks Hospital in London it was common practice that all APC mutation carriers with multiple adenomas - independent of number and size - had surgery at the age of 18 (personal communication, Professor Robin Phillips).

However, colorectal surgery in FAP patients carries a high (psycho)social cost due to the timing of surgery in a phase of life (15-25 years) in which individuals usually study and prepare for a job or career, and often seek a marriage partner. Furthermore, some studies have shown that (proctoand/or subtotal) colectomy is associated with a substantial decrease in quality of life [8-15], and in up to $10 \%$ of patients colorectal surgery may provoke the development of desmoid tumours [16]. Obviously, those patients requiring surgery need to be carefully selected and the decision for surgical intervention should be taken cautiously.

In recent years, the quality of colonoscopy has been substantially improved by the introduction of high definition (HD) colonoscopes and by the use of indigo carmine, allowing the detection of very small polyps. In addition, large 
numbers of polyps, including polyps of considerable size, can now be resected using endoscopic mucosal resection (EMR) or endoscopic submucosal resection (ESD). The importance of these improvements was recently emphasized in a Japanese study of FAP patients who refused surgery, which showed that polypectomy can be used to remove large numbers of polyps in an apparently safe manner [17]. Various guidelines on the timing and indications for colectomy are currently available, including NCCN (www.NCCN. org), ACG and InSiGHT $[18,19]$.

In the present retrospective study, we evaluated decision making with respect to the surgical management of a large series of patients with FAP, taking the above guidelines into consideration.

Our specific aims were: (1) to evaluate age at surgery over the course of time and (2) to assess the natural history of adenoma development over the course of time in initially untreated patients.

\section{Patients and methods}

For the purposes of this retrospective study, the Dutch Polyposis Registry database was consulted in order to identify and retrieve all data, since 1985, on patients with FAP known to the Family Cancer Clinic at the Department of Gastroenterology \& Hepatology of Leiden University Medical Centre. The following information was collected for all patients: gender, age at diagnosis, genetic diagnosis or clinical FAP, age at surgery and pathological findings (adenomatous polyps or $(R C)$. The patients were subdivided into two groups: Group A consisted of patients diagnosed before 2000 and group $B$ comprised patients diagnosed in 2000 or later.

The presence of $>100$ adenomas was classified as classical polyposis. Attenuated FAP was generally defined as the presence of $<100$ adenomas in a patient older than 30 years $[20,21]$. All patients in which colorectal surgery is considered are discussed by a Multidisciplinary Group in which surgeons and gastroenterologists are involved.

For patients with polyposis who initially did not undergo surgery because most adenomas were $<5 \mathrm{~mm}$, detailed information was collected on the outcome of subsequent colonoscopies, including the estimated number of adenomas, the estimated size of the adenomas, whether polypectomy was performed, the use of sulindac/arthrocine, and for those patients that eventually underwent colectomy, the indication for surgery and pathological findings.

Descriptive statistics were used to characterize the study population. Frequencies are presented as absolute numbers and percentages. Continuous data are presented as means (standard deviation (SD)), and in the case of non-normally distributed data, as median (range). The observation time was from 1-1-1985 until 1-7-18.

All patients included in the Polyposis Registry provided written informed consent for registration. The study protocol conforms to the ethical guidelines of the Helsinki Declaration.

\section{Results}

\section{Leiden cohort of (A)FAP patients}

The Family Cancer Clinic at the Leiden University Medical Centre had records on a total of 72 patients with FAP registered since 1985. An underlying APC mutation was detected in 69 of the 72 patients, and three patients had a clinical diagnosis of polyposis ( $>100$ adenomas). A total of 33 patients were diagnosed before 2000 (group A) and 39 in 2000 or later (group B).

\section{Classical FAP}

Fifty-two patients were diagnosed with classical FAP. The median age at diagnosis was 18 (8-38) years in group $A$ and also 18 (7-63) years in group B. All patients diagnosed before 2000 underwent colorectal surgery, whereas $68 \%$ of the patients diagnosed $>2000$ had undergone surgery. The median age at surgery was 19 (10-39) years in group $A$ and 24 (7-64) years in group B.

\section{Attenuated FAP}

Twenty patients showed an attenuated form of polyposis. The median age at diagnosis was 41.5 (30-50) years in group A and 28 (16-61) years in group B. All patients diagnosed before 2000 underwent colorectal surgery, whereas $29 \%$ of the patients diagnosed $>2000$ had undergone surgery. The ages at surgery in group A varied from 31 to 60 years and in group B from 36 to 51 years. The ages at diagnosis and surgery are summarized in Table 1.

\section{Follow-up colonoscopies in patients with surgery postponed}

In nine patients with classical FAP and one 19 years-old patient with 50 adenomas, surgery was initially postponed because most adenomas were $<5 \mathrm{~mm}$. The mean follow-up time was 7.9 years (range: 1-17 years). Follow-up colonoscopies showed that the estimated number of adenomas gradually increased over the years. Although most adenomas remained $<5 \mathrm{~mm}$ in all patients, the proportion of adenomas between 5 and $10 \mathrm{~mm}$ slowly increased. Four patients developed adenomas $>10 \mathrm{~mm}$. Only one patient developed a high-grade adenoma and none of the patients developed

Table 1. Age at diagnosis and colorectal surgery in patients with classical FAP and attenuated familial adenomatous polyposis (AFAP) before (group A) and after 2000 (group B).

\begin{tabular}{lcc}
\hline & Group A $<2000$ & Group B $\geq 2000$ \\
\hline Total number of (A)FAP patients & 33 & 39 \\
Gender (M/F) (\% M) & $16 \mathrm{M} / 17 \mathrm{~F}(50 \%)$ & $17 \mathrm{M} / 22 \mathrm{~F}(42 \%)$ \\
Patients with classical FAP & 27 & 25 \\
Median age at diagnosis (years) & $18(8-38)$ & $18(7-63)$ \\
Proportion with colorectal surgery & $100 \%$ & $68 \%$ \\
Median age at surgery (years) & $19(10-39)$ & $24(7-64)$ \\
Patients with AFAP & 6 & 14 \\
Median age at diagnosis (years) & $41.5(30-50)$ & $28(16-61)$ \\
Proportion with colorectal surgery & $100 \%$ & $29 \%(4 / 14)$ \\
Ages at surgery (years) & $60,50,39,39,31,52$ & $39,37,36,51$ \\
\hline
\end{tabular}


CRC. Two patients were treated with sulindac (arthrocine), which had a substantial effect on the number of adenomas. One patient with multiple adenomas $>5 \mathrm{~mm}$ and a few $>10 \mathrm{~mm}$ subsequently underwent surgery. Another patient, in whom a large number of adenomas of $5-10 \mathrm{~mm}$ were resected, preferred a colectomy after a follow-up of 10 years. Both patients recovered well after surgery and did not encounter any complications.

Table 2 provides detailed information on the outcome of the subsequent colonoscopies in these 10 patients, including the estimated number of the adenomas, size, polypectomies performed, pathology and sulindac (arthrocine) treatment.

\section{Discussion}

In this retrospective study, we evaluated the timing and decision making regarding surgical management in a large series of patients with FAP who attended the Leiden Family Cancer Clinic over the last 30 years. The study demonstrated that patients with classical FAP who had surgery $\geq 2000$ were on average 5 years older than patients $<2000$. In patients with classical polyposis who initially did not undergo colectomy, endoscopic follow-up showed that the number of adenomas $(<5 \mathrm{~mm})$ slowly increased and more patients developed adenomas between 5 and $10 \mathrm{~mm}$. Only a few of these patients developed adenomas $>10 \mathrm{~mm}$. No colorectal cancers were observed during follow-up.

The improved identification of patients, the implementation of colorectal surveillance and early surgical treatment have together significantly improved the prognosis for FAP patients [22-25]. Surgical treatment by procto- or subtotal colectomy usually takes place between the ages of 15 and 25 years [1]. Judgement on the timing of surgical intervention is complex and depends on many issues, but generally includes (1) endoscopic findings, (2) genotype, (3) the FAP phenotype in the family, (4) a patient's wishes, (5) desire to have children, (6) compliance with surveillance, (7) endoscopic difficulties, (8) risk of desmoid tumours (which, if increased, is a reason to postpone surgery as long as possible) and (9) social issues. It is well known that procto- or subtotal colectomy may be associated with a decreased functional outcome and may have a major impact on the well-being of patients in this age category [8-15,26]. The decision for surgical intervention should therefore be taken cautiously.

Our study suggests that postponement of colorectal surgery has become more common in recent decades. Due to major improvements in the identification and removal of large numbers of adenomas, we are now technically able to postpone surgery in most FAP patients, even in those with $>100$ adenomas (classic polyposis as defined by Bussey) [2]. This was clearly demonstrated by Japanese colleagues who removed $\sim 50,000$ adenomas from 90 patients with classical FAP who refused surgery. No CRC was observed after 5 years of follow-up.

However, although the risk of developing CRC at ages younger than 20 years appears to be very low [1], the risk of CRC in patients with multiple small adenomas in older patients is still unknown. Postponing surgery might therefore lead to the development of cancer and this risk should be discussed with the patient [27].

How can current guidelines help guide the endoscopic or surgical management of polyposis patients? The three most important sets of guidelines have been produced by the National Comprehensive Cancer Network (NCCN), American College of Gastroenterology (ACG) and the International Society of Gastrointestinal Hereditary Tumours (InSiGHT) [18]. These recommendations are summarized in Table 3.

According to NCCN guidelines, surgery may be considered in AFAP patients $>21$ years with fewer than 20 (nonadvanced) adenomas. In our view and experience, this approach is too aggressive. On the other hand, the recommendation that surgery should be offered to patients with advanced adenomas ( $>1 \mathrm{~cm}$, advanced histology) that are unmanageable with polypectomy seems appropriate. Other suitable indications for early prophylactic surgery established by the ACG include polyps $>1 \mathrm{~cm}$, polyps with $H G D, a$ marked increase in polyp number and symptoms.

In patients with AFAP, endoscopic follow-up and polypectomy is recommended. Both the NCCN and ACG guidelines provide specific recommendations for patients with AFAP. However, it should be noted that in clinical practice it can be difficult to differentiate patients with classic FAP and AFAP. While diagnoses of AFAP in a patient $>30$ years and less than 100 adenomas or of classic FAP in a patient $<20$ years with 100-1000's of adenomas may be clear, some patients aged 20-30 years have intermediate numbers (50-100) of adenomas. We therefore recommend that a diagnosis of AFAP or classical FAP should be disregarded in favour of recommendations for surgery based solely on the number and size of adenomas and the feasibility of adenoma removal.

Recently, the InSiGHT group proposed a detailed staging system for polyposis of the colon that can be used in decision making on surgical treatment [18]. All recommendations seem to be appropriate and helpful. The only requirement that is not practical in the clinic appears to concern the specific number of adenomas. In our experience, the estimation of polyp numbers exceeding 100 is unreliable. We would therefore suggest that estimates of polyp numbers be limited to $<20$, between 20 and 100 and $>100$, and that the focus be shifted to the number of large adenomas, i.e., $>5 \mathrm{~mm}$ or $>10 \mathrm{~mm}$. We propose new practical guidelines that place a greater emphasis on the number of adenomas $>5 \mathrm{~mm}$ (Leiden Guidelines for management of colorectal polyposis in FAP) (Table 4).

A strength of this study was the evaluation of patient care over a long period of time (approximately 30 years). A limitation of the study was that the colonoscopies were performed by different doctors, including both gastroenterologists in training (supervised by certified gastroenterologists) as well as very experienced doctors. This may partly explain some of the variation in the estimated numbers of colorectal adenomas. However, this is also a reflection of normal clinical practice. 


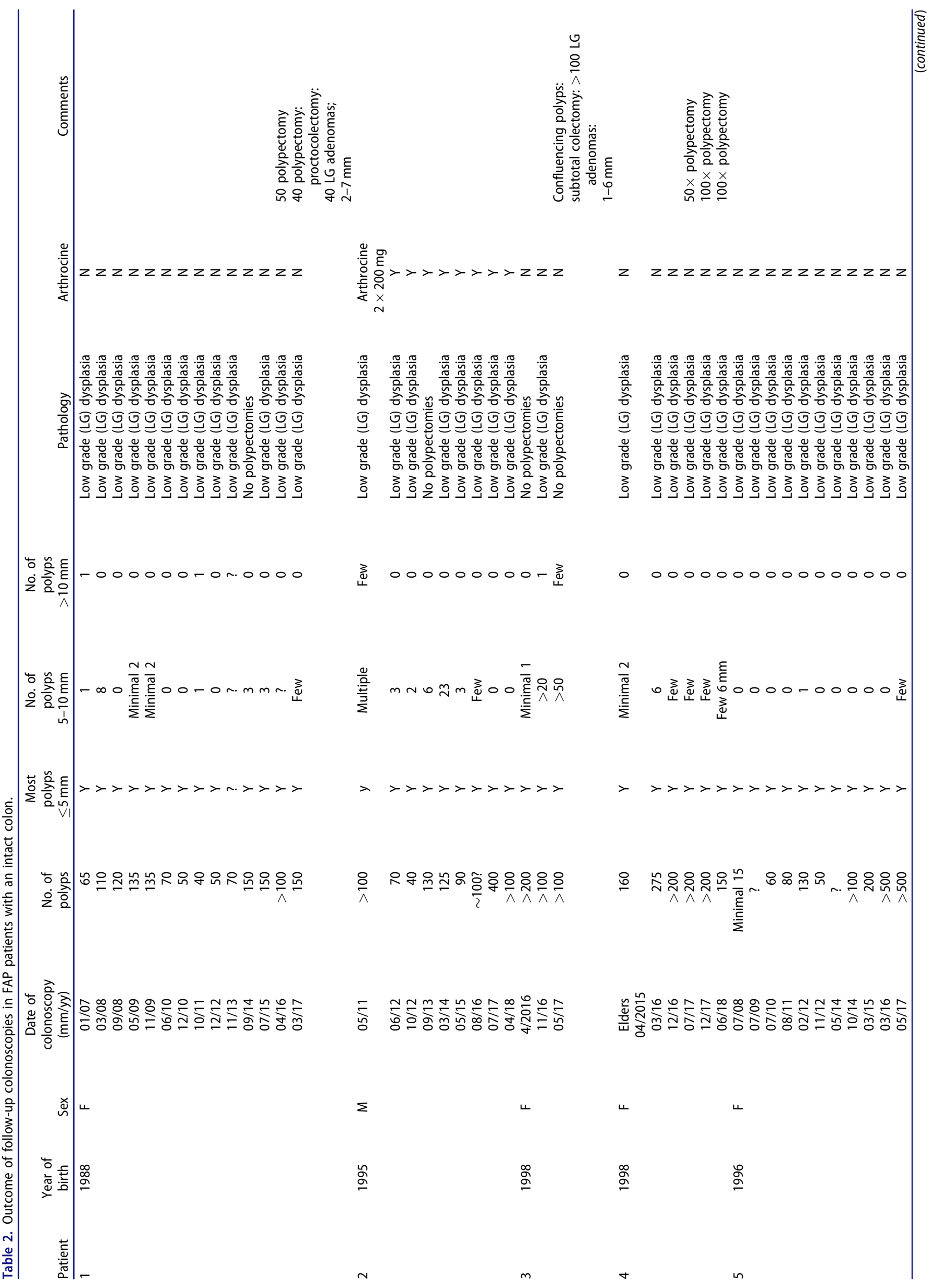




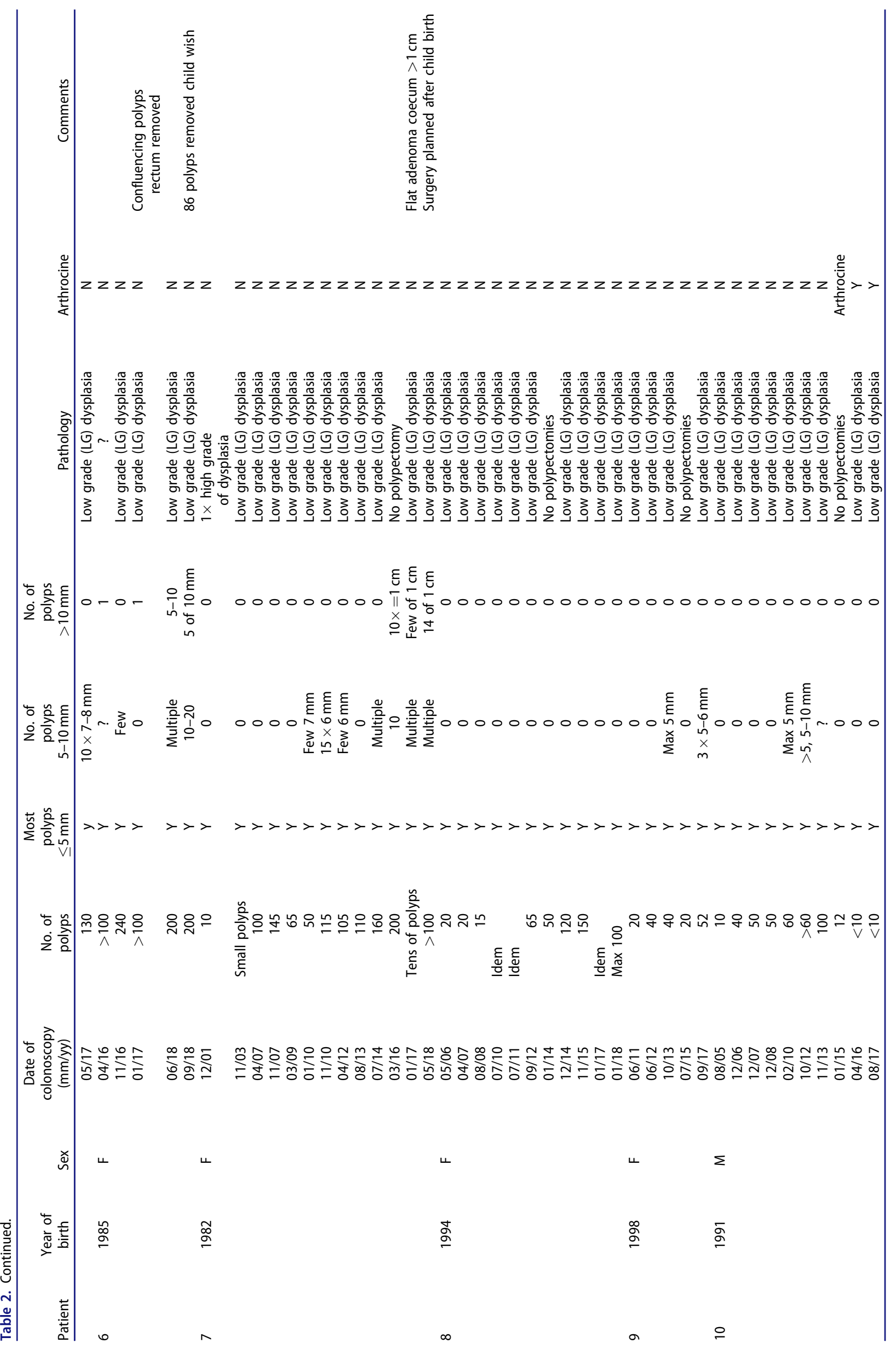


Table 3. Summary of recommendations of (procto)(subtotal)colectomy in familial adenomatous polyposis according to various guidelines.

\section{National Comprehensive Cancer Network (NCCN) 2018}

FAP patients $<18$ years

AFAP patients $<21$ years with $<20$ adenomas (all $<1 \mathrm{~cm}$ and non-advanced pathology)

AFAP patients $>21$ years with $<20$ non-advanced adenomas

Patients with significant polyposis (not manageable with polypectomy)

American College of Gastroenterology (ACG) 2015

Absolute indications for immediate colorectal surgery in FAP, AFAP and MAP

Relative indications for surgery

Prophylactic surgery can be planned at a suitable time (late teens to early twenties)

Indications for early surgery
Timing of surgery of patients without severe polyposis and without a family history of early CRC or severe genotype is not established and can be individualized

Colonoscopy every 1-2 years and polypectomy

Colonoscopy every 1-2 years and polypectomy or surgery (IRA) might be considered Surgery recommended

Colonoscopic polypectomy and may possibly never need colectomy Patients with attenuated polyposis (AFAP)

International Society of Hereditary Gastrointestinal Tumours Polyposis Staging System Colon 2016

\begin{tabular}{|c|c|c|c|}
\hline Stage & Polyp description & Clinical intervention & Comments \\
\hline 0 & $<20$ polyps, all $<5 \mathrm{~mm}$ & Colonoscopy/2 years & Biopsy at baseline \\
\hline $1^{\mathrm{a}}$ & $20-200$ polyps, most $<5 \mathrm{~mm}$, none $>1 \mathrm{~cm}$ & Colonoscopy/1 year & $\begin{array}{l}\text { Some consider surgery, especially with } \\
\text { high numbers }\end{array}$ \\
\hline $2^{\mathrm{a}}$ & $\begin{array}{l}200-500 \text { polyps and }<10 \text { adenomas that } \\
\text { are }>1 \mathrm{~cm}\end{array}$ & $\begin{array}{l}\text { Colonoscopy } / 1 \text { year, } \\
\text { polypectomy preferred }\end{array}$ & Alternative surgery \\
\hline $3^{a}$ & $\begin{array}{l}500-1000 \text { polyps or any other number if } 10-50 \\
\text { polyps are }>1 \mathrm{~cm} \text { and amenable to complete } \\
\text { polypectomy }\end{array}$ & Colonoscopy/6-12 months or colectomy & $\begin{array}{l}\text { Removal large polyps defensible if clear reason } \\
\text { for postpone surgery }\end{array}$ \\
\hline 4 & $\begin{array}{l}>1000 \text { polyps and/or any polyps grown to } \\
\text { confluence and not amenable to simple } \\
\text { polypectomy; any invasive cancer }\end{array}$ & (procto)colectomy within 3-12 months & $\begin{array}{l}\text { Any delay in surgery sh. be individualized and } \\
\text { based on compelling circumstances }\end{array}$ \\
\hline
\end{tabular}

aPresence of high-grade dysplasia warrants upgrading to stage 4 .

Table 4. Leiden scoring system and guidelines for management of colorectal polyposis in FAP.

\begin{tabular}{|c|c|c|c|c|}
\hline Stage & $\begin{array}{l}\text { Number of } \\
\text { adenomas }\end{array}$ & Size & Intervention & Interval colonoscopy \\
\hline 1 & $<20$ & $\begin{array}{l}\text { Most }<5 \mathrm{~mm} \\
\text { few }>5 \mathrm{~mm} \\
\text { no adenomas }>10 \mathrm{~mm}\end{array}$ & $\begin{array}{l}\text { Colonoscopy and polypectomy } \\
\text { all polyps }>5 \mathrm{~mm}\end{array}$ & $1-2$ years \\
\hline 2 & $20-100$ & $\begin{array}{l}\text { Most }<5 \mathrm{~mm} \\
\text { few }>5 \mathrm{~mm}, \\
\text { no adenomas }>10 \mathrm{~mm}\end{array}$ & $\begin{array}{l}\text { Colonoscopy and polypectomy } \\
\text { all polyps }>5 \mathrm{~mm}\end{array}$ & 1 year \\
\hline 3 & $>100$ & $\begin{array}{l}\text { Most }<5 \mathrm{~mm}, \\
\text { multiple }>5 \mathrm{~mm} \text {, } \\
\text { few }>10 \mathrm{~mm} \text {, amenable to simple } \\
\text { polypectomy }\end{array}$ & $\begin{array}{l}\text { Colonoscopy and polypectomy } \\
\text { all polyps }>5 \mathrm{~mm} \text { or } \\
\text { consider surgery }\end{array}$ & 6-12 months \\
\hline 4 & $>100$ & $\begin{array}{l}\text { Most }<5 \mathrm{~mm} \text {, } \\
\text { but a substantial number }>5 \mathrm{~mm} \text { and/or } \\
>10 \mathrm{~mm} \text {, not amenable to simple } \\
\text { polypectomy or the presence of } \\
\text { confluencing polyps or the presence of } \\
\text { adenomas with high grade dysplasia }\end{array}$ & (procto)colectomy & $\begin{array}{l}\text { If surgery is postponed, } \\
\text { colonoscopy within } \\
3-6 \text { months }\end{array}$ \\
\hline
\end{tabular}

What are the implications of our findings for clinical practice? Our observations suggest that although prevention of CRC is the first responsibility of the physician and colectomy remains the primary treatment for colonic polyposis, in selected patients strict colonic surveillance and polypectomy can be an appropriate treatment over a long period. The decision to perform surgery should be taken only after thoroughly discussing all relevant issues with the patients. If a final decision regarding surgery is made, the appropriate technique of surgery depends of the number and size of the rectal adenomas. In cases with very mild or absent rectal polyposis, we recommend a subtotal colectomy with an ileorectal anastomosis whereas a proctocolectomy with construction of an ileal-pouch anal anastomosis is recommended in patients with multiple large rectal adenomas.

The NCCN and ACG guidelines are useful in the decisionmaking process as they provide general indications for early surgery. The InSiGHT guidelines provide more detailed recommendations, which are based on both numbers and size of adenomas. The latter guidelines could be improved by paying more attention to the number of large adenomas $(>5 \mathrm{~mm}$ and $>10 \mathrm{~mm}$ ) instead of counting many very small 
adenomas. Future prospective studies should evaluate whether postponement of surgery in selected patients is safe.

\section{Disclosure statement}

No potential conflict of interest was reported by the authors.

\section{References}

[1] Vasen HF, Moslein G, Alonso A, et al. Guidelines for the clinical management of familial adenomatous polyposis (FAP). Gut. 2008; 57:704-713.

[2] Bussey H. Familial polyposis coli. Baltimore: The John Hopkins University Press; 1975.

[3] Burt RW, Leppert MF, Slattery ML, et al. Genetic testing and phenotype in a large kindred with attenuated familial adenomatous polyposis. Gastroenterology. 2004;127:444-451.

[4] Nieuwenhuis MH, Vasen HF. Correlations between mutation site in APC and phenotype of familial adenomatous polyposis (FAP): a review of the literature. Crit Rev Oncol Hematol. 2007;61:153-161.

[5] Barrow P, Khan M, Lalloo F, et al. Systematic review of the impact of registration and screening on colorectal cancer incidence and mortality in familial adenomatous polyposis and Lynch syndrome. Br J Surg. 2013;100:1719-1731.

[6] Bulow S, Bulow C, Nielsen TF, et al. Centralized registration, prophylactic examination, and treatment results in improved prognosis in familial adenomatous polyposis. Results from the Danish Polyposis Register. Scand J Gastroenterol. 1995;30: 989-993.

[7] Moslein G. Surgical considerations in FAP-related pouch surgery: could we do better? Fam Cancer. 2016;15:457-466.

[8] Van Duijvendijk P, Slors JF, Taat CW, et al. Quality of life after total colectomy with ileorectal anastomosis or proctocolectomy and ileal pouch-anal anastomosis for familial adenomatous polyposis. Br J Surg. 2000;87:590-596.

[9] Schneider R, Schneider C, Dalchow A, et al. Prophylactic surgery in familial adenomatous polyposis (FAP) - a single surgeon's short- and long-term experience with hand-assisted proctocolectomy and smaller J-pouches. Int J Colorectal Dis. 2015;30: 1109-1115.

[10] Ganschow P, Pfeiffer U, Hinz U, et al. Quality of life ten and more years after restorative proctocolectomy for patients with familial adenomatous polyposis coli. Dis Colon Rectum. 2010;53: 1381-1387.

[11] Hassan I, Chua HK, Wolff BG, et al. Quality of life after ileal pouch-anal anastomosis and ileorectal anastomosis in patients with familial adenomatous polyposis. Dis Colon Rectum. 2005;48: 2032-2037.
[12] Fazio VW, Kiran RP, Remzi FH, et al. Ileal pouch anal anastomosis: analysis of outcome and quality of life in 3707 patients. Ann Surg. 2013;257:679-685.

[13] Wolf ND, Kadmon M, Wolf RC, et al. Quality of life after restorative proctocolectomy and ileal pouch-anal anastomosis in patients with familial adenomatous polyposis: a matter of adjustment. Colorectal Dis. 2011;13:e358-e365.

[14] Gunther K, Braunrieder G, Bittorf BR, et al. Patients with familial adenomatous polyposis experience better bowel function and quality of life after ileorectal anastomosis than after ileoanal pouch. Colorectal Dis. 2003;5:38-44.

[15] Douma KF, Bleiker EM, Vasen HF, et al. Quality of life and consequences for daily life of familial adenomatous polyposis (FAP) family members. Colorectal Dis. 2011;13:669-677.

[16] Nieuwenhuis MH, Lefevre $\mathrm{JH}$, Bulow $\mathrm{S}$, et al. Family history, surgery, and APC mutation are risk factors for desmoid tumors in familial adenomatous polyposis: an international cohort study. Dis Colon Rectum. 2011;54:1229-1234.

[17] Ishikawa $H$, Mutoh $M$, Iwama T, et al. Endoscopic management of familial adenomatous polyposis in patients refusing colectomy. Endoscopy. 2016;48:51-55.

[18] Lynch PM, Morris JS, Wen S, et al. A proposed staging system and stage-specific interventions for familial adenomatous polyposis. Gastrointest Endosc. 2016;84:115-125e4.

[19] Syngal S, Brand RE, Church JM, et al. ACG clinical guideline: genetic testing and management of hereditary gastrointestinal cancer syndromes. Am J Gastroenterol. 2015;110:223-262.

[20] Knudsen AL, Bulow S, Tomlinson I, et al. Attenuated familia adenomatous polyposis: results from an international collaborative study. Colorectal Dis. 2010;12:e243-e249.

[21] Nielsen M, Hes FJ, Nagengast FM, et al. Germline mutations in APC and MUTYH are responsible for the majority of families with attenuated familial adenomatous polyposis. Clin Genet. 2007;71: 427-433.

[22] Heiskanen I, Luostarinen T, Jarvinen HJ. Impact of screening examinations on survival in familial adenomatous polyposis. Scand J Gastroenterol. 2000;35:1284-1287.

[23] Bulow C, Bulow S, Nielsen TF, et al. [Prognosis in familial adenomatous polyposis. Results from the Polyposis Registry]. Ugeskr Laeg. 1996;158:4188-4190.

[24] Bjork J, Akerbrant $H$, Iselius L, et al. Epidemiology of familial adenomatous polyposis in Sweden: changes over time and differences in phenotype between males and females. Scand J Gastroenterol. 1999;34:1230-1235.

[25] Bulow S. Results of national registration of familial adenomatous polyposis. Gut. 2003;52:742-746.

[26] van Duijvendijk P, Slors JF, Taat CW, et al. Functional outcome after colectomy and ileorectal anastomosis compared with proctocolectomy and ileal pouch-anal anastomosis in familial adenomatous polyposis. Ann Surg. 1999;230:648-654.

[27] Kaz AM, Dominitz JA. Can individuals with colonic polyposis be managed safely with colonoscopic surveillance? Endoscopy. 2016; $48: 7-8$. 